\title{
Predictive value of IL-18 and IL-10 in the prognosis of patients with colorectal cancer
}

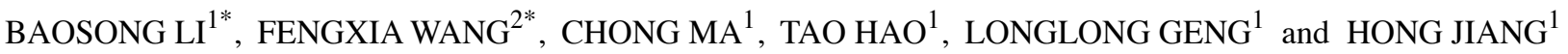 \\ Departments of ${ }^{1}$ Colorectal and Anal Surgery and ${ }^{2}$ Laboratory, \\ Binzhou Medical University Hospital, Binzhou, Shandong 256603, P.R. China
}

Received November 26, 2018; Accepted April 15, 2019

DOI: $10.3892 / \mathrm{ol} .2019 .10338$

\begin{abstract}
Predictive value of serum interleukin 10 (IL-10) and interleukin 18 (IL-18) expression in patients with colorectal cancer (CRC) was investigated. This study retrospectively analyzed the medical records of 146 patients with CRC admitted to the Binzhou Medical University Hospital as the study group, and collected the physical examination data of 82 volunteers as the control group. The expression levels of IL-10 and IL-18 in the serum were measured by enzyme-linked immunosorbent assay (ELISA). A 60-month follow-up on patients in the study group was performed to make records of their prognosis. The expressions of IL-10 and IL-18 were statistically different in patients with different Dukes' stages, tumor sizes, histological grades, and different situations of distant metastasis of cancer cells $(\mathrm{P}<0.05)$; with a gradual downward trend following the operation. The expression levels of serum IL-10 and IL-18 in the study group 7 days after the operation were lower than the levels before the operation $(\mathrm{P}<0.05)$, and the expression levels of IL-10 and IL-18 of patients in the study group on the day of discharge were lower than the expression levels 7 days after the operation $(\mathrm{P}<0.05)$. The expressions of IL-10 and IL-18 of patients with reoccurred $\mathrm{CRC}$ after the operation were significantly higher than that of patients without recurrence of CRC in the study group $(\mathrm{P}<0.05)$. Thus, IL-10 and IL-18 are highly expressed in the serum of CRC patients, which makes IL-10 and IL-18 useful to serve as indicators to determine the prognosis of CRC patients. The lower the expression levels of IL-10 and IL-18, the lower the cancer recurrence rate, the better the prognosis and the longer the survival time.
\end{abstract}

Correspondence to: Dr Hong Jiang, Department of Colorectal and Anal Surgery, Binzhou Medical University Hospital, 661 Huanghe 2 Road, Binzhou, Shandong 256603, P.R. China

E-mail: j6v2rv@163.com; 957963980@qq.com

*Contributed equally

Key words: interleukin-10, interleukin-18, colorectal cancer, recurrence, survival time

\section{Introduction}

As a malignant tumor of the digestive tract with quite a common occurrence, colorectal cancer (CRC) has the third highest incidence worldwide (1). Without a clarified etiology, $\mathrm{CRC}$ is currently considered to be a consequence of a common coordination effect of eating habits, living habits, environment, genetic and other factors (2). Due to the developed economy, accelerated life rhythm, and the changed living environment, as well as a common diet characterized with low fiber, high fat, and high protein, the incidence and mortality of CRC are increasing each year. With few obvious symptoms in the early stage except for discomfort and indigestion, CRC develops more symptoms at the middle and late stage when the distant metastasis of cancer cells occurs, including stool bleeding, abdominal pain, intestinal obstruction, change of bowel habit, weight loss or fever (3). Due to the lack of specific clinical manifestations in the early stage of CRC, patients often receive no correct treatment in the optimal treatment period because of misdiagnosis and missed diagnosis. Some patients even start seeking medical help at the middle and late stages of cancer, losing the chance of radical surgery and receiving unsatisfactory efficacy from routine treatment (4). Studies have revealed disappointing 5-year survival rate of CRC, only approximately $65 \%$, along with a poor prognosis with a recurrence rate of $37 \%$ (5).

As a type of cytokine produced by a variety of cells and acting on a variety of cells, the interleukin family plays a pivotal role in the differentiation, maturation, proliferation, activation, immune regulation, and mediated inflammatory response of immune cells, involved in a variety of physiological and pathological reactions (6).

Interleukin 10 (IL-10) has a two-way immunomodulatory effect, mainly negative immunomodulatory effects (7). Mainly produced by monocytes, activated B cells, and keratinocytes, IL-10 is located on chromosome 1 of the human body and has a molecular weight of 35-40 kDa, in the main form of a dimer (8). IL-10 can not only inhibit the synthesis of a variety of cytokines such as various inflammatory factors and growth factors, and promote the secretion of anti-inflammatory factors in the body, but also can inhibit effector molecules to achieve tumor immunosuppression, being able to be produced by various types of solid tumors and hematopoietic tumors (9). 
Interleukin 18 (IL-18), a $1.1 \mathrm{~kb}$-long cytokine that is located on chromosome 11 (11q22.2-22.3), consists of 6 exogenous factors and 5 inclusions, with 157 amino acids and a molecular weight of $18.3 \mathrm{kDa}(10)$. As an inflammatory cytokine that is mainly produced by macrophages, T cells, B cells, osteoblasts, glial cells, and other cells, IL-18 plays a vital role in the inflammatory response of cells (11). Previous findings have shown that overexpression of the IL-18 protein can reduce the viability of tongue squamous cell carcinoma cells by inducing apoptosis to importantly inhibit the growth and development of tongue squamous cell carcinoma cells (12). However, the role of IL-18 in the occurrence and development of diseases is controversial. It has been previously shown that the expression of IL-18 in the endometrium of female patients with polycystic ovary syndrome is significantly increased compared with that in normal women, with higher expression of IL-18 in the uterus of overweight patients with polycystic ovary syndrome than in the uterus of polycystic ovary syndrome patients with normal weight (13). Thus IL-18 may play opposite roles in different tumors or diseases.

Considering the unclear role of IL-10 and IL-18 in CRC, this study investigated the expression of IL-10 and IL-18 in serum of patients with CRC and explored the clinical relationship between IL-10 and IL-18 and the clinical stage, tumor differentiation and post-treatment prognosis of CRC patients, as well as the value of IL-10 and IL-18 in evaluating the prognosis of patients with $\mathrm{CRC}$, with the purpose of providing references for clinical practice.

\section{Patients and methods}

Clinical baseline data. This study used a retrospective analysis of the medical records of 146 patients with CRC admitted to Binzhou Medical University Hospital (Binzhou, China) from January 2011 to May 2013 and the physical examination data of 82 healthy volunteers who underwent a physical examination during the same period. A total of 146 patients ( 84 males and 62 females, with an average age of $56.43 \pm 16.43$ years) who received colonoscopy before the treatment and were confirmed by pathology as CRC patients were enrolled in the study group, 82 healthy volunteers (44 males and 38 females, with an average age of $54.32 \pm 15.69$ years) were enrolled in the control group. This study was conducted after the approval by the Medical Ethics Committee of Binzhou Medical University Hospital, and both the patients and their families signed the informed consent form.

Inclusion and exclusion criteria. The inclusion criteria were: patients with the first-listed diagnosis of CRC, patients who were older than or equal to 18 years, patients who received regular follow-up after the surgery, patients who did not undergo radiotherapy and chemotherapy before admission, patients who were willing to be re-examined in Binzhou Medical University Hospital regularly after discharge.

The exclusion criteria were: those who were treated in Binzhou Medical University Hospital with reoccurred CRC, those with diabetes, those with immune disease, those with cardiovascular and cerebrovascular diseases, those who suffered from intestinal obstruction complicated with intestinal bleeding before the treatment.
Main reagents and instruments. IL-10 ELISA kit (Shanghai Haling Biological Technology Co., Ltd., Shanghai, China; article number: HL10289); IL-18 ELISA kit (Shanghai Yuanmu Biotechnology Co., Ltd., Shanghai, China; article number: YM-QP10207); fully-automatic quantitative enzyme standard instrument (Anthos Labtec Instruments $\mathrm{GmbH}$, als-Siezenheim, Austria; article number: anthos2010); and UV-visible spectrophotometer (UV1700; Runqee Instrument Technology Co., Ltd., Shanghai, China) were used in the present study.

\section{Experimental methods}

Collection of experimental specimens. All participants in the experiment were fasted for more than $8 \mathrm{~h}$ in the night before blood collection. Elbow venous blood $(5 \mathrm{ml})$ on an empty stomach was extracted the next morning and stored in the refrigerator for $12 \mathrm{~h}$. After the refrigeration, the blood sample was taken out and placed at $30^{\circ} \mathrm{C}$ for $25 \mathrm{~min}$ at $4^{\circ} \mathrm{C}$, then was centrifugalized at the speed of $800 \mathrm{x}$ g for $5 \mathrm{~min}$ at $4^{\circ} \mathrm{C}$. Ten minutes of standing followed the end of the centrifugation to wait for the stratification of the blood sample. Then the supernatant liquid was carefully collected and stored at $-20^{\circ} \mathrm{C}$.

Determination of $I L-10$ and $I L-18$ expression levels. In this experiment, the expression levels of IL-10 and IL-18 in the serum of patients in the study group and the control group were determined by enzyme-linked immunosorbent assay (ELISA).

The blood sample to be tested and the kit were taken out from the refrigerator, and thawed at room temperature at $30^{\circ} \mathrm{C}$. Next, the ELISA plate was taken out, and $50 \mu \mathrm{l}$ of the standard product was added into the standard well, $10 \mu \mathrm{l}$ of the sample and $40 \mu \mathrm{l}$ of the sample dilution solution were added into the sample well, $100 \mu \mathrm{l}$ of the chromogenic antibody was added to each well except the blank well. After that, the ELISA plate was put in a water bath at $37^{\circ} \mathrm{C}$ for $60 \mathrm{~min}$ and then taken out, and $50 \mu \mathrm{l}$ of the washing solution was added to each well and was removed after $1 \mathrm{~min}$ of standing, such washing was repeated 5 times. Afterwards, $50 \mu \mathrm{l}$ of the enzyme standard solution was added to each well (except the blank well) which was then put in the shaking water bath for $15 \mathrm{~min}$ at $37^{\circ} \mathrm{C}$. Following that, the color developing agent was added to each well (except the blank well) to perform the color reaction for 15 min in the dark. Finally, the reaction was terminated by the addition of a stop solution. The absorbance of each well was measured at a wavelength of $450 \mathrm{~nm} 10 \mathrm{~min}$ after the end of the reaction. The ratio of the absorbance of the sample to the absorbance of the standard product was calculated according to the absorbance corresponding to the concentration of the standard product, and the samples with a ratio of its absorbance to the absorbance of the standard product was $\leq 99 \%$ were determined as qualified for the experiment. The measured absorbance and the linear regression equation were calculated by the automatic microplate reader, and the concentration of the sample was measured.

Observation indicators and follow-up methods of the study group. After the surgical operation and the discharge from hospital, patients in the study group were followed up for 60 months. For patients who were in good health and could maintain contact, the follow-up was mainly performed by telephone; for patients with poor communication by telephone 
Table I. Comparison of general baseline data between the study group and the control group [n (\%)] (mean \pm SD).

\begin{tabular}{|c|c|c|c|c|}
\hline Factors & Study group $(n=146)$ & Control group $(n=82)$ & $\chi^{2} / \mathrm{t}$ & P-value \\
\hline Age (years) & $56.43 \pm 16.52$ & $54.32 \pm 15.69$ & 0.942 & 0.347 \\
\hline Sex & & & 0.320 & 0.581 \\
\hline Male & $84(57.53)$ & $44(53.66)$ & & \\
\hline Female & $62(42.47)$ & $38(46.34)$ & & \\
\hline Body mass index $\left(\mathrm{kg} / \mathrm{m}^{2}\right)$ & & & 0.049 & 0.890 \\
\hline$<24$ & $77(52.74)$ & $42(51.22)$ & & \\
\hline$\geq 24$ & $69(47.26)$ & $40(48.78)$ & & \\
\hline Smoking status & & & 0.485 & 0.493 \\
\hline Yes & $80(54.79)$ & $41(50.00)$ & & \\
\hline No & $66(45.21)$ & $41(50.00)$ & & \\
\hline Alcohol abuse & & & 0.417 & 0.579 \\
\hline Yes & $67(45.89)$ & $34(41.46)$ & & \\
\hline No & $79(54.11)$ & $48(58.54)$ & & \\
\hline Fasting blood sugar $(\mathrm{mmol} / \mathrm{l})$ & $4.35 \pm 1.81$ & $4.63 \pm 1.48$ & 1.194 & 0.234 \\
\hline Marriage history & & & 0.453 & 0.591 \\
\hline Married & $137(93.84)$ & $75(91.46)$ & & \\
\hline Unmarried & $9(6.16)$ & 7 (8.54) & & \\
\hline $\mathrm{Hb}(\mathrm{g} / \mathrm{l})$ & $123.58 \pm 18.43$ & $126.97 \pm 15.63$ & 1.405 & 0.161 \\
\hline $\operatorname{RBC}\left(\times 10^{12} / 1\right)$ & $4.60 \pm 0.38$ & $4.49 \pm 0.49$ & 1.886 & 0.061 \\
\hline $\operatorname{PLT}\left(\mathrm{x} 10^{9} / 1\right)$ & $216.35 \pm 57.26$ & $224.89 \pm 48.21$ & 1.142 & 0.255 \\
\hline
\end{tabular}

interview, such as those of senior age, in poor health or died during the follow-up, follow-up was performed by visiting or consulting their families as appropriate. To record the recurrence situation of the disease, patients in the study group were required to receive B-scan ultrasonography, colonoscopy, and CT examinations every 3 months in the first year after the discharge, every 6 months in the second year after the discharge, and once a year in the third year after the discharge. No examinations in the hospital were required three years after the discharge.

Statistical analysis. Statistical analysis was performed by SPSS 17.0 (Beijing Strong-Vinda Information Technology Co., Ltd., Beijing, China), and the expression levels of IL-10 and IL-18 were expressed as the mean \pm standard deviation (mean $\pm \mathrm{SD}$ ). The t-test was used to compare the measurement data between groups, the Chi-square test was used to compare the count data between groups, while the variance test and LSD post hoc test were used to compare the measurement data of multi-group. The Kaplan-Meier method and the log-rank test were used for survival analysis. The difference was statistically significant at $\mathrm{P}<0.05$.

\section{Results}

Baseline data. No statistical differences of the baseline data between the study group and the control group were identified including the age, sex, body mass index, smoking status, alcohol abuse, fasting blood glucose, marriage history, $\mathrm{Hb}$ value, $\mathrm{RBC}$ value and PLT value $(\mathrm{P}>0.05)$ (Table I).

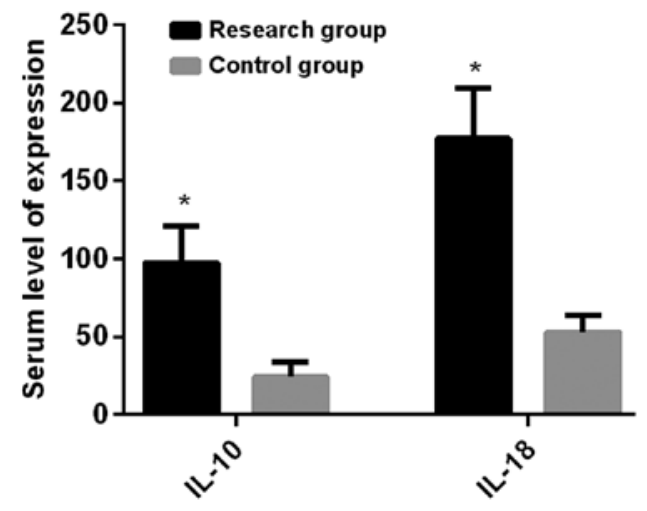

Figure 1. Comparison of IL-10 and IL-18 expression levels between the study group and the control group. The expression levels of IL-10 and IL-18 in the serum of the study group were statistically higher than those of the control group according to the ELISA test results $(\mathrm{P}<0.05)$. Asterisk $\left(^{*}\right)$ indicates that the difference was statistically significant when compared with the control group. IL-10, interleukin 10; IL-18, interleukin 18.

Expression of $I L-10$ and $I L-18$ in the two groups. Both the expression level of IL-10 $(97.36 \pm 23.51 \mathrm{ng} / \mathrm{l})$ and the expression level of IL-18 $(176.98 \pm 32.34 \mathrm{ng} / \mathrm{l})$ in the serum of the study group before surgery were higher than those of the control group which had a serum IL-10 expression level of $(24.53 \pm 9.23) \mathrm{ng} / \mathrm{l}$ and a serum IL-18 expression level of $(52.93 \pm 11.09) \mathrm{ng} / \mathrm{l}$, and the difference was statistically significant $(\mathrm{P}<0.05)$ (Fig. 1).

Relationship between the serum IL-10 and IL-18 and the clinicopathology of $C R C$ in the study group. According to the results, the expression of IL-10 and IL-18 in the study 
Table II. Comparison of expression of IL-10 and IL-18 in different clinical and pathological conditions in the study sroup $($ mean $\pm \mathrm{SD})$.

\begin{tabular}{|c|c|c|c|c|c|c|c|}
\hline Factor & Study group $(\mathrm{n}=146)$ & IL-10 (ng/l) & $\mathrm{t} / \mathrm{F}$ & P-value & IL-18 (ng/l) & $\mathrm{t} / \mathrm{F}$ & P-value \\
\hline Age (years) & & & 1.716 & 0.088 & & 1.821 & 0.071 \\
\hline$<55$ & 67 & $93.45 \pm 19.60$ & & & $170.45 \pm 25.81$ & & \\
\hline$\geq 55$ & 79 & $99.34 \pm 21.53$ & & & $179.02 \pm 30.30$ & & \\
\hline Sex & & & 0.899 & 0.370 & & 1.462 & 0.146 \\
\hline Male & 84 & $95.11 \pm 21.26$ & & & $172.99 \pm 28.35$ & & \\
\hline Female & 62 & $98.39 \pm 22.48$ & & & $180.03 \pm 29.29$ & & \\
\hline \multicolumn{8}{|l|}{ Body mass index $\left(\mathrm{kg} / \mathrm{m}^{2}\right)$} \\
\hline$<24$ & 77 & $94.83 \pm 20.98$ & 1.506 & 0.134 & $181.06 \pm 28.26$ & 1.517 & 0.131 \\
\hline$\geq 24$ & 69 & $100.05 \pm 20.82$ & & & $173.84 \pm 29.20$ & & \\
\hline Dukes' staging & & & 9.474 & $<0.01$ & & 4.406 & $<0.01$ \\
\hline Stage A and B & 53 & $83.88 \pm 10.03$ & & & $169.41 \pm 24.77$ & & \\
\hline Stage $C$ and $D$ & 93 & $105.82 \pm 15.05$ & & & $187.02 \pm 22.30$ & & \\
\hline Tumor size (cm) & & & 7.138 & $<0.01$ & & 7.748 & $<0.01$ \\
\hline$<4$ & 61 & $85.36 \pm 11.51$ & & & $158.94 \pm 14.30$ & & \\
\hline$\geq 4$ & 85 & $103.54 \pm 17.33$ & & & $185.48 \pm 23.84$ & & \\
\hline Histological grades & & & 64.150 & $<0.01$ & & 131.000 & $<0.01$ \\
\hline Well differentiated & 43 & $82.84 \pm 8.99$ & & & $154.95 \pm 10.31$ & & \\
\hline Moderately differentiated & 56 & $94.93 \pm 13.08^{\mathrm{a}}$ & & & $178.43 \pm 12.57^{\mathrm{a}}$ & & \\
\hline Poorly differentiated & 47 & $109.84 \pm 11.03^{\mathrm{a}}$ & & & $196.27 \pm 13.05^{\mathrm{a}}$ & & \\
\hline Distant metastasis & & & 8.082 & $<0.01$ & & 11.340 & $<0.01$ \\
\hline Yes & 82 & $106.35 \pm 14.52$ & & & $192.94 \pm 16.38$ & & \\
\hline No & 64 & $87.36 \pm 13.51$ & & & $161.53 \pm 16.89$ & & \\
\hline
\end{tabular}

${ }^{\mathrm{a}} \mathrm{P}<0.05$ indicates that the difference was statistically significant when compared with the well differentiated group. IL-10, interleukin 10 ; IL-18, interleukin 18.

group were not statistically related with factors including age, sex and body mass index $(\mathrm{P}>0.05)$, but were statistically significant for factors such as the Dukes' staging, tumor size, histological grades, and the distant metastasis of cancer cells $(\mathrm{P}<0.05)$ (Table II).

Expression of $I L-10$ and $I L-18$ in the study group before and after the operation. The results presented a gradual decrease of the expression of IL-10 and IL-18 in the serum of the study group after the operation, from $(97.36 \pm 23.51) \mathrm{ng} / \mathrm{l}$ of IL-10 before the operation to $(85.23 \pm 19.40) \mathrm{ng} / \mathrm{l}$ of IL-10 7 days after the operation, from $(176.98 \pm 32.34) \mathrm{ng} / \mathrm{l}$ of IL-18 before the operation to $(159.34 \pm 29.94) \mathrm{ng} / \mathrm{l}$ of IL-18 7 days after the operation, and the differences were statistically significant $(\mathrm{P}<0.05)$. In addition, the expression of IL-10 on the day of discharge $(78.49 \pm 17.43 \mathrm{ng} / \mathrm{l})$ and the expression of IL-18 $(145.95 \pm 26.91 \mathrm{ng} / \mathrm{l})$ on the day of discharge were statistically lower than the expression of IL-10 and IL-18 7 days after the operation $(\mathrm{P}<0.05)$ (Fig. 2).

Relationship between the expression levels of IL-10 and $I L-18$ and the recurrence of the disease in the study group. After the discharge, the IL-10 expression of patients in the study group confirmed by the examination reports to

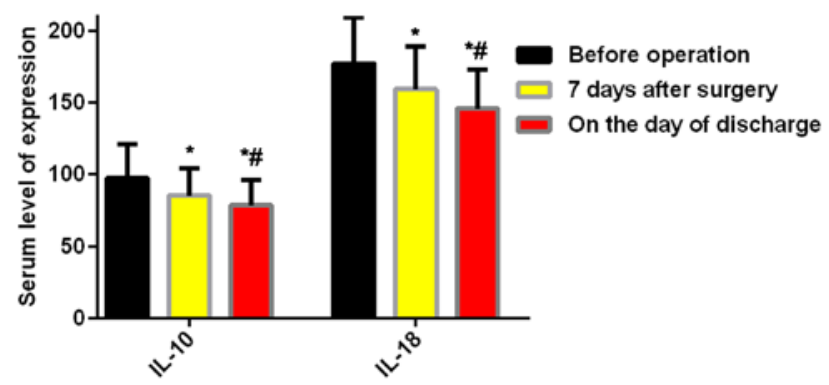

Figure 2. Comparison of IL-10 and IL-18 expression levels before and after surgery in the study group. The ELISA results show a gradual decrease of the expression of IL-10 and IL-18 in the serum of the study group after the operation, and indicated that the expression levels of IL-10 and IL-18 7 days after the operation were lower than those before the operation, and were statistically different $(\mathrm{P}<0.05)$. In addition, the expression of IL-10 and IL-18 on the day of discharge were statistically lower than the expression of IL-10 and IL-18 7 days after the operation $(\mathrm{P}<0.05) .{ }^{*} \mathrm{P}<0.05$, a statistically significant difference when compared with the preoperative expression levels; ${ }^{\#} \mathrm{P}<0.05$, a statistically significant difference when compared with the expression levels 7 days after the operation. IL-10, interleukin 10; IL-18, interleukin 18.

be reoccurred disease after the operation on the day of the detection of recurrence of cancer cells was $(77.48 \pm 27.45) \mathrm{ng} / \mathrm{l}$, significantly higher than the serum expression level of IL-10 of patients without reoccurred cancer cells $(43.65 \pm 13.56) \mathrm{ng} / \mathrm{l}$ 
Table III. Relationship between expression levels and recurrence of IL-10 and IL-18 in the study group (mean \pm SD).

\begin{tabular}{lccccrr}
\hline Factor & $\mathrm{n}$ & $\mathrm{IL}-10(\mathrm{ng} / \mathrm{l})$ & $\mathrm{t}$ & P-value & IL-18 (ng/l) & $\mathrm{t}$ \\
\hline Recurrence & & & 9.886 & $<0.01$ & & 33.970 \\
Yes & 58 & $77.48 \pm 27.45$ & & & $153.45 \pm 14.54$ & $<0.01$ \\
No & 88 & $43.65 \pm 13.56$ & & & $84.37 \pm 10.04$ & \\
\hline
\end{tabular}

IL-10, interleukin 10; IL-18, interleukin 18.

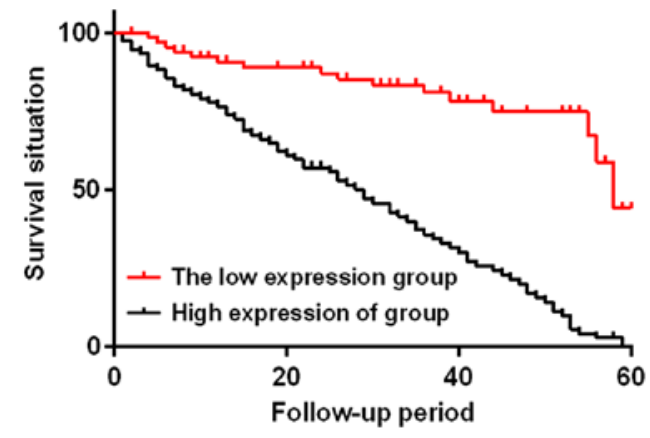

Figure 3. The relationship between the IL-10 expression level and the survival of patients in the study group. The Kaplan-Meier test results showed that the median time of survival of the IL-10 low expression group was 58 months, statistically different from the IL-10 high expression group which had a median survival time of 29 months $\left(\chi^{2}=49.330, \mathrm{P}<0.01\right)$. At the end of the follow-up, the number of deaths in the IL-10 low-expression group reached 16 with a mortality rate of $23.18 \%$; the number of deaths in the IL-10 high-expression group reached 72 with a mortality rate of $93.51 \%$. IL-10, interleukin 10; IL-18, interleukin 18.

according to the last examination reports, and the difference was statistically significant $(\mathrm{P}<0.01)$. The IL-18 expression of patients with reoccurred disease after the operation on the day of the detection of recurrence of cancer cells was $(153.45 \pm 14.54) \mathrm{ng} / \mathrm{l}$, significantly higher than the serum expression level of IL-18 of patients without reoccurred cancer cells which was $(84.37 \pm 10.04) \mathrm{ng} / \mathrm{l}$ according to the last examination reports, and the difference was statistically significant $(\mathrm{P}<0.05)$ (Table III).

Relationship between the IL-10 expression level and the survival of patients in the study group. According to the average expression level of serum IL-10 in the study group on the day of discharge, patients in the study group were divided into two subgroups, with 69 patients whose IL-10 expression levels were $<75 \mathrm{ng} / \mathrm{l}$ in the low IL-10 expression group and 77 patients whose IL-10 expression levels were $\geq 75 \mathrm{ng} / \mathrm{l}$ in the high IL-10 expression group. The two subgroups were followed up for 60 months. At the end of the follow-up, the low IL-10 expression group had 16 cases of death, with a median survival time of 58 months and a mortality rate of $23.18 \%$; the high IL-10 expression group had 72 cases of death, with a median survival time of 29 months and a mortality rate of $93.51 \%$. The two subgroups were statistically different $\left(\chi^{2}=49.330\right.$, $\mathrm{P}<0.01$ ) (Fig. 3).

Relationship between the IL-18 expression level and the survival of patients in the study group. According to the

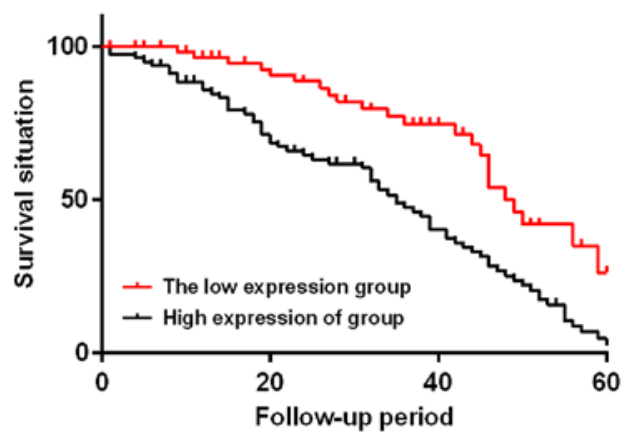

Figure 4. The relationship between the IL-18 expression level and the survival of patients in the study group. The Kaplan-Meier test results showed that the median time of survival of the IL-18 low expression group was 49 months, statistically different from the IL-18 high expression group which had a median survival time of 35 months $\left(\chi^{2}=15.290, \mathrm{P}<0.01\right)$. At the end of the follow-up, the number of deaths in the IL-18 low-expression group reached 21 with a mortality rate of $38.18 \%$, and the number of deaths in the IL-18 high-expression group reached 67 with a mortality rate of $73.63 \%$. IL-10, interleukin 10; IL-18, interleukin 18.

average expression level of serum IL-18 in the study group on the day of discharge, patients in the study group were divided into two subgroups, with 55 patients whose IL-18 expression levels were $<150 \mathrm{ng} / 1$ in the low IL-18 expression group and 91 patients whose IL-18 expression levels were $\geq 150 \mathrm{ng} / \mathrm{l}$ in the high IL-18 expression group. The two subgroups were followed up for 60 months. At the end of the follow-up, the low IL-18 expression group had 21 cases of death, with a median survival time of 49 months and a mortality rate of $38.18 \%$; the high IL-18 expression group had 67 cases of death, with a median survival time of 35 months and a mortality rate of $73.63 \%$. The two subgroups were statistically different $\left(\chi^{2}=15.290\right.$, $\mathrm{P}<0.01)$ (Fig. 4).

\section{Discussion}

Colorectal cancer (CRC), a very common tumor disease, has a serious impact on human health due to its high morbidity and mortality (14). In recent years, CRC has shown an increase in incidence and a tendency of a younger age of onset (15), accounting for more than $15 \%$ of all systemic malignant tumors (16). CRC mostly affects individuals aged approximately 55 years (17), seriously threatening the safety of human life with high mortality. Most of the CRC patients start their treatment at an advanced cancer stage when radiotherapy brings very limited efficacy due to the patients' poor sensitivity to it, leading to treatment options such as surgical resection. However, surgical resection, with its huge surgical trauma, is harmful to the postoperative recovery 
and survival of patients, resulting in a low recovery rate and an easy recurrence or metastasis of cancer cells (18).

Tumor growth is closely related to the regulation of the body's immune system (19). IL-10, an immunosuppressive factor with strong immunosuppressive effects, mainly performs its function of regulating immune response through presenting antigens to $T$ cells in various ways (20). In the process of tumor occurrence and development, IL-10 is of importance as an immunosuppressive factor by promoting the aggravation of the body's inflammatory response, accelerating the occurrence and development of tumors through the mechanism of immunosuppression, and further advancing tumor progression by further increasing its expression when the tumor deteriorates forming a vicious circle (21). IL-18, as a cytokine characterized by ubiquity and pleiotropy can promote inflammation and immune stimulation, it has double roles in inhibiting and promoting the occurrence and development of human immune system diseases (22). Mainly secreted by monocytes and macrophages, IL-18 can significantly enhance the body's immune function (23). In recent years, IL-18 has been reported increasingly in literature to be possibly synthesized by tumor cells, with an especially high expression in oral cancer patients (24).

This study detected that the levels of IL-10 and IL-18 in the serum of CRC patients were higher than those in healthy people, with a statistical difference $(\mathrm{P}<0.05)$, which is similar to the findings of Haghshenas et al (25) who discovered the higher average expression of IL-18 in gastrointestinal cancer patients compared to healthy volunteers in the detection of the expression of IL-18 in the serum of gastrointestinal cancer patients. Galizia et al (26) discovered the increase of IL-10 expression in mice which received a subcutaneous injection of CRC cells, which is similar to the findings of this study. In further research, our study found the expressions of IL-10 and IL-18 in CRC patients were not statistically related with factors including age, gender and body mass index $(\mathrm{P}>0.05)$, but were in statistical relation to factors such as the Dukes' staging, tumor size, histological grades and the distant metastasis of cancer cells $(\mathrm{P}<0.05)$; a gradual decrease of the expression of IL-10 and IL-18 in CRC patients surfaced after surgery and thus the expression levels of IL-10 and IL-18 in the serum 7 days after the operation were statistically lower than those before the operation $(\mathrm{P}<0.05)$; in addition, the expression of IL-10 and IL-18 on the day of discharge were also lower than those 7 days after the operation, with a statistical difference between them $(\mathrm{P}<0.05)$. Jablonska et al (24) found that the expression of IL-18 in the serum of patients with oral squamous cell carcinoma 3 weeks after the surgery was lower than that before surgery, and the study by Becker et al (27) revealed that patients with colon cancer had a lower expression of serum IL-10 after the treatment compared with that before the treatment. This study also found that the expression of IL-10 in patients with reoccurred CRC after the operation was statistically significantly higher than that in patients without recurrence of $C R C(P<0.01)$, similar to the expression of IL-18 $(\mathrm{P}<0.01)$. This study divided patients in the study group into two subgroups according to the IL-10 expression, with 69 patients whose IL-10 expression levels were $<75 \mathrm{ng} / 1$ in the low IL-10 expression group and 77 patients whose IL-10 expression levels were $\geq 75 \mathrm{ng} / \mathrm{l}$ in the high IL-10 expression group. The two subgroups were followed up for 60 months the low IL-10 expression group had 16 cases of death, with a median survival time of 49 months and a mortality rate of $23.18 \%$; the high IL-10 expression group had 72 cases of death, with a median survival time of 29 months and a mortality rate of $93.51 \%$. The two subgroups were statistically different $\left(\chi^{2}=49.330, \mathrm{P}<0.01\right)$. Such findings were similar to the study results of Miteva et al (28), who found that CRC patients with a high preoperative serum IL-10 levels had low survival rates, indicating the poor prognosis and survival of CRC patients with high serum IL-10 levels. Next, patients in the study group were divided into two subgroups according to the IL-18 expression, with 55 patients whose IL-18 expression levels were $<150 \mathrm{ng} / \mathrm{l}$ in the low IL-18 expression group and 91 patients whose IL-18 expression levels were $\geq 150 \mathrm{ng} / \mathrm{l}$ in the high IL-18 expression group. The two subgroups were followed up for 60 months, the low IL-18 expression group had 21 cases of death, with a median survival time of 49 months and a mortality rate of $38.18 \%$; the high IL-18 expression group had 67 cases of death, with a median survival time of 35 months and a mortality rate of $73.63 \%$. The two subgroups were statistically different $\left(\chi^{2}=15.290, \mathrm{P}<0.01\right)$, showing that a high level of serum IL-18 led to a poor prognosis and survival of CRC patients. Dwivedi et al (21) discovered the ability of IL-10 to promote tumorigenesis and systemic tumor immune suppression and speculated that the cause of poor prognosis of patients with high IL-10 expression might be the IL-10 function of damaging the activation of the cytotoxic T lymphocyte and inhibiting its cytolysis activity. Okamoto et al (29) found that serum IL-18 was an independent prognostic factor for patients with non-small cell lung cancer, and serum IL-18 expression levels in patients with non-small cell lung cancer with bone metastases were significantly higher than those without bone metastases, which is similar to this study.

This study strictly selected the research subjects according to the inclusion and exclusion criteria to ensure the reliability of the results of this study. A 60-month follow-up study was performed for the prognosis of CRC patients, period, mainly through monthly telephone interviews, home visits, or consultations with the patients' relatives to guarantee the accuracy and reality of the result. The accuracy of this study was also guarded by the precise records of the prognosis of patients according to the reports of B-scan ultrasonography, colonoscopy, and CT examinations every 3 months in the first year after the discharge, every 6 months in the second year after the discharge, and once a year in the third year after the discharge.

IL-10 and IL-18 have high expression in the serum of CRC patients and have a close relationship with the Dukes' staging, tumor size, histological grade, and distant metastasis of cancer cells. IL-10 and IL-18 can be used as indicators to judge the prognosis of CRC patients, specifically the lower the expression levels of IL-10 and IL-18, the lower the recurrence rate of cancer, the better the prognosis and the longer the survival time.

\section{Acknowledgements}

Not applicable. 


\section{Funding}

The study was supported by the Binzhou Science and Technology Development Plan Project (project no. 2014ZCO107).

\section{Availability of data and materials}

The datasets used and/or analyzed during the present study are available from the corresponding author on reasonable request.

\section{Authors' contributions}

BL drafted the manuscript. BL and FW put forward the proposition, designed the study and performed ELISA. CM and TH were responsible for the clinical baseline data collection. LG and $\mathrm{HJ}$ assisted with the collection of the experimental specimens. All authors read and approved the final manuscript.

\section{Ethics approval and consent to participate}

This study was approved by the Medical Ethics Committee of Binzhou Medical University Hospital (Binzhou, China). Patients who participated in this research had complete clinical data. Signed informed consents were obtained from the patients or their guardians.

\section{Patient consent for publication}

Not applicable.

\section{Competing interests}

The authors declare that they have no competing interests.

\section{References}

1. Ren XL, He GY, Li XM, Men H, Yi LZ, Lu GF, Xin SN, Wu PX, Li YL, Liao WT, et al: MicroRNA-206 functions as a tumor suppressor in colorectal cancer by targeting FMNL2. J Cancer Res Clin Oncol 142: 581-592, 2016.

2. Burden ST, Hill J, Shaffer JL and Todd C: Nutritional status of preoperative colorectal cancer patients. J Hum Nutr Diet 23: 402-407, 2010.

3. Rasmussen S, Larsen PV, Søndergaard J, Elnegaard S Svendsen RP and Jarbøl DE: Specific and non-specific symptoms of colorectal cancer and contact to general practice. Fam Pract 32 387-394, 2015.

4. Cerdán-Santacruz C, Cano-Valderrama O, Cárdenas-Crespo S, Torres-García AJ and Cerdán-Miguel J: Colorectal cancer and its delayed diagnosis: Have we improved in the past 25 years? Rev Esp Enferm Dig 103: 458-463, 2011.

5. Zippi M,De Toma G, Minervini G,Cassieri C, Pica R, Colarusso D, Stock S and Crispino P: Desmoplasia influenced recurrence of disease and mortality in stage III colorectal cancer within five years after surgery and adjuvant therapy. Saudi J Gastroenterol 23: 39-44, 2017.

6. Chaudhry H,Zhou J,Zhong Y, Ali MM, McGuire F, Nagarkatti PS and Nagarkatti M: Role of cytokines as a double-edged sword in sepsis. In Vivo 27: 669-684, 2013.

7. Liu M, Zhao X, Ma Y, Zhou Y, Deng M and Ma Y: Transcription factor c-Maf is essential for IL-10 gene expression in B cells. Scand J Immunol 88: e12701, 2018.

8. Tabibzadeh S, Becker JL and Parsons AK: Endometriosis is associated with alterations in the relative abundance of proteins and IL-10 in the peritoneal fluid. Front Biosci 8: a70-a78, 2003.

9. Hamzavi M, Tadbir AA, Rezvani G, Ashraf MJ, Fattahi MJ Khademi B, Sardari Y and Jeirudi N: Tissue expression, serum and salivary levels of IL-10 in patients with head and neck squamous cell carcinoma. Asian Pac J Cancer Prev 14: 1681-1685, 2013.
10. Wu SQ, Liang W, Wang GL, Li LY, Wang DL and Chen C: Polymorphisms of the IL-18 promoter and bronchial asthma. Mol Med Rep 6: 1385-1388, 2012.

11. Cornish J, Gillespie MT, Callon KE, Horwood NJ, Moseley JM and Reid IR: Interleukin-18 is a novel mitogen of osteogenic and chondrogenic cells. Endocrinology 144: 1194-1201, 2003.

12. Liu W, Hu M, Wang Y, Sun B, Guo Y, Xu Z, Li J and Han B: Overexpression of interleukin-18 protein reduces viability and induces apoptosis of tongue squamous cell carcinoma cells by activation of glycogen synthase kinase-3 $\beta$ signaling. Oncol Rep 33: 1049-1056, 2015.

13. Long X, Li R, Yang Y and Qiao J: Overexpression of IL-18 in the proliferative phase endometrium of patients with polycystic ovary syndrome. Reprod Sci 24: 252-257, 2017.

14. Ress AL, Perakis S and Pichler M: microRNAs and colorectal cancer. Adv Exp Med Biol 889: 89-103, 2015.

15. Goldvaser H, Purim O, Kundel Y, Shepshelovich D, Shochat T, Shemesh-Bar L, Sulkes A and Brenner B: Colorectal cancer in young patients: Is it a distinct clinical entity? Int J Clin Oncol 21: 684-695, 2016

16. Zheng Y and Wu C: Prevalence and trend of gastrointestinal malignant tumors in the elderly over 75 years old in China. Zhonghua Wei Chang Wai Ke Za Zhi 19: 481-485, 2016 (In Chinese).

17. Castells A: Prevention of colorectal cancer. Med Clin (Barc) 117: 69-75, 2001 (In Spanish).

18. Hind R, Rew DR and Johnson CD: Surgical excision alone is adequate treatment for primary colorectal cancer. Ann R Coll Surg Engl 74: 63-67, 1992.

19. Sio A, Chehal MK, Tsai K, Fan X, Roberts ME, Nelson BH, Grembecka J, Cierpicki T, Krebs DL and Harder KW: Dysresgulated hematopoiesis caused by mammary cancer is associated with epigenetic changes and hox gene expression in hematopoietic cells. Cancer Res 73: 5892-5904, 2013.

20. Mittal SK and Roche PA: Suppression of antigen presentation by IL-10. Curr Opin Immunol 34: 22-27, 2015.

21. Dwivedi S, Goel A, Natu SM, Mandhani A, Khattri S and Pant KK: Diagnostic and prognostic significance of prostate specific antigen and serum interleukin 18 and 10 in patients with locally advanced prostate cancer: A prospective study. Asian Pac J Cancer Prev 12: 1843-1848, 2011.

22. Amerio P, Frezzolini A, Abeni D, Teofoli P, Girardelli CR, De Pità $\mathrm{O}$ and Puddu P: Increased IL-18 in patients with systemic lupus erythematosus: Relations with Th-1, Th-2, pro-inflammatory cytokines and disease activity. IL-18 is a marker of disease activity but does not correlate with pro-inflammatory cytokines. Clin Exp Rheumatol 20: 535-538, 2002.

23. Li X, Ren D, Li Y, Xu J, Liu C and Zhao Y: Increased cancer risk associated with the $-607 \mathrm{C} / \mathrm{A}$ polymorphism in interleukin-18 gene promoter: An updated meta-analysis including 12,502 subjects. J BUON 20: 902-917, 2015.

24. Jablonska E, Puzewska W, Grabowska Z, Jablonski J and Talarek L: VEGF, IL-18 and NO production by neutrophils and their serum levels in patients with oral cavity cancer. Cytokine 30: 93-99, 2005.

25. Haghshenas MR, Hosseini SV, Mahmoudi M, Saberi-Firozi M, Farjadian S and Ghaderi A: IL-18 serum level and IL-18 promoter gene polymorphism in Iranian patients with gastrointestinal cancers. J Gastroenterol Hepatol 24: 1119-1122, 2009.

26. Galizia G, Orditura M, Romano C, Lieto E, Castellano P, Pelosio L, Imperatore V, Catalano G, Pignatelli C and De Vita F: Prognostic significance of circulating IL-10 and IL-6 serum levels in colon cancer patients undergoing surgery. Clin Immunol 102: 169-178, 2002.

27. Becker C, Fantini MC, Wirtz S, Nikolaev A, Lehr HA, Galle PR, Rose-John S and Neurath MF: IL-6 signaling promotes tumor growth in colorectal cancer. Cell Cycle 4: 217-220, 2005.

28. Miteva LD, Stanilov NS, Deliysky TS and Stanilova SA: Significance of $-1082 \mathrm{~A} / \mathrm{G}$ polymorphism of IL-10 gene for progression of colorectal cancer and IL-10 expression. Tumour Biol 35: 12655-12664, 2014.

29. Okamoto M, Azuma K, Hoshino T, Imaoka H, Ikeda J, Kinoshita T, Takamori S, Ohshima K, Edakuni N, Kato S, et al: Correlation of decreased survival and IL-18 in bone metastasis. Intern Med 48: 763-773, 2009.

This work is licensed under a Creative Commons Attribution-NonCommercial-NoDerivatives 4.0 International (CC BY-NC-ND 4.0) License. 